\title{
Elementos da Representação Social da Aids Agrupados em Dimensões: Uma Técnica Estrutural
}

\author{
Jean Carlos Natividade ${ }^{1}$ \\ Brígido Vizeu Camargo \\ Universidade Federal de Santa Catarina
}

\begin{abstract}
RESUMO - Este estudo demonstra a possibilidade de caracterização da estrutura da representação social da Aids através do grau de valorização simbólica de elementos. Essa técnica fornece dados intervalares sobre a importância atribuída aos elementos da representação social e possibilita o cálculo de correlações entre eles.
\end{abstract}

Palavras-chave: representação social, Aids, métodos de pesquisa.

\section{Elements of Social Representations of Aids Grouped in Dimensions: A Structural Technique}

\begin{abstract}
This study shows the possibility of characterizing the structure of social representation of AIDS through the degree of symbolic value attributed to the elements. This technique provides interval data on the importance given to the elements of the social representation and allows the calculation of correlations between them.
\end{abstract}

Keywords: social representation, AIDS, research methods.

As representações sociais podem ser entendidas como um conhecimento compartilhado socialmente por um grupo sobre um determinado objeto. Elas são, ao mesmo tempo, um conteúdo mental estruturado e conscientemente compartilhado com outros membros do grupo social e um processo público de criação, mudança, elaboração e difusão de conhecimento (Wagner, 1998). Além de fornecerem noções para o estabelecimento de relações de simbolização entre um objeto e um grupo, as representações sociais embasam e norteiam práticas (Abric, 2001).

A comunicação, sobretudo a linguagem, é responsável pela formação desse conhecimento compartilhado (Moscovici, 2003) e, no processo de formação das representações sociais, palavras ou expressões ganham qualificação de elementos caracterizadores que se relacionam entre si dando forma às representações. Tais elementos organizam-se em uma estrutura específica, de maneira hierarquizada e com um núcleo central; em torno deste núcleo situam-se elementos periféricos (Abric, 2001). Essa estrutura de elementos simbólicos interconectados no núcleo define a representação social (Flament, 2001).

Pesquisas estruturais geralmente são conduzidas através da técnica de evocação livre, em que os participantes devem citar, em ordem, certo número de palavras que lhes vêm à memória quando pensam em determinado objeto. Além disso, são avaliadas por meio de análise prototípica, gráficos elaborados a partir das frequências das palavras citadas e das suas ordens de evocações, e/ou por gráficos de conexidade, construídos a partir da coocorrência de citação de elementos. Natividade (2010) apontou limitações em determinar a

1 Endereço para correspondência: Instituto de Psicologia, sala 101, Laboratório de Mensuração. Rua Ramiro Barcelos, 2600 - Bairro Santa Cecília - Porto Alegre - RS - Brasil. CEP 90035-003 Fone: (51) 3308-5066 representação social da aids através da análise prototípica, salientando que a inexistência de critérios estatísticos para definir a pertença de um elemento a um quadrante tornaria a caracterização da estrutura propensa à influência do acaso.

Considerando o exposto, elaborou-se este estudo com o objetivo de verificar a possibilidade de caracterização da representação social da aids através do grau de valorização simbólica de seus elementos representativos. Essa técnica se propõe a fornecer dados intervalares sobre a importância atribuída aos elementos da representação do objeto em questão, a fim de possibilitar o estabelecimento de correlações entre eles. Foram utilizados 10 elementos (descritos na sessão instrumentos) demarcados como centrais para representação social da aids em estudos anteriores para diversas populações (Camargo, Barbará, \& Bertoldo, 2007; Flores-Palacios \& Leyva-Flores, 2003; Goodwin et al., 2003; Marques, Oliveira, \& Gomes, 2004).

\section{Método}

\section{Participantes}

Participaram 480 adultos com média de idade de 25,4 anos $(D P=8,2$ anos), sendo 67,7\% mulheres. Quanto à escolaridade, $20 \%$ dos participantes tinham de nove a 11 anos de estudo, $55,8 \%$ de 12 a 15 anos de estudo e $24,2 \%$ mais de 15 anos de estudo.

\section{Instrumentos}

Utilizou-se como instrumento de pesquisa um questionário autoaplicável, de respostas fechadas, com questões 
sociodemográficas como sexo, idade e escolaridade; e uma escala de valorização simbólica de elementos da representação social da aids. Os itens da escala apresentavam os elementos cuidado, doença, medo, morte, preconceito, prevenção, preservativo, responsabilidade, sexo e sofrimento, cada um em uma frase, para que os estudantes julgassem o quanto cada um deles estaria vinculado à aids, variável entre $1=$ certamente não relacionado a $5=$ certamente relacionado. Por exemplo: marque na escala o quanto você considera que termo cuidado está relacionado à Aids.

\section{Procedimentos}

Os participantes foram localizados através de quatro instituições de ensino de Santa Catarina, uma de ensino médio para jovens e adultos, uma de ensino de graduação, uma de pós-graduação e uma de graduação e pós-graduação. Após contato com responsáveis pelas instituições, agendaram-se as aplicações coletivas por turmas, durante os horários e nos próprios locais onde os participantes tinham aulas. Posteriormente, calcularam-se as médias de valorização atribuída a cada elemento, de forma que quanto mais o elemento era considerado relacionado à aids (mais próximo do 5), maior sua valorização enquanto representativo do objeto em questão. Para testar as relações entre os elementos e agrupar aqueles mais vinculados entre si efetuou-se uma análise de extração de componentes principais com rotação Direct Oblimin.

\section{Resultados}

As médias de valorização dos elementos enquanto representativos da aids podem ser visualizadas na Tabela 1 . Destacam-se como os de maiores valores atribuídos os elementos prevenção e preservativos, enquanto para o elemento morte observa-se a menor média de valorização simbólica.

A matriz de correlações apontou um número significativo de ligações entre os elementos (teste de esfericidade de Bartlett, $p<0,001)$ e a amostra mostrou-se adequada à fato-

Tabela 1. Médias e desvios padrões da valorização dos elementos das representações sociais da aids.

\begin{tabular}{lcc}
\hline Elementos & Média & Desvio Padrão \\
\hline prevenção & 4,84 & 0,57 \\
preservativo & 4,81 & 0,61 \\
cuidado & 4,66 & 0,78 \\
sexo & 4,64 & 0,79 \\
responsabilidade & 4,58 & 0,94 \\
doença & 4,50 & 0,85 \\
sofrimento & 4,26 & 1,03 \\
medo & 4,09 & 1,16 \\
preconceito & 4,06 & 1,29 \\
morte & 3,90 & 1,18 \\
\hline
\end{tabular}

rização $(K M O=0,71)$. Quanto ao número de componentes, obtiveram-se os seguintes dados: eigenvalue maior que $1=$ três componentes; Scree plot de Catell = três componentes; variância explicada para três dimensões $=53,6 \%$. A maior correlação entre os componentes foi de r=-0,26 (dimensão 1 e dimensão 3); entre a dimensão1 e a dimensão 2 a correlação foi de $\mathrm{r}=0,14$; já entre a dimensão 2 e dimensão 3 a correlação foi de $r=-0,12$. A Tabela 2 apresenta os elementos que compuseram cada dimensão e suas cargas componenciais, os valores de cargas dos elementos abaixo de 0,45 foram suprimidos.

\section{Discussão}

As médias de valorização simbólica foram superiores ao ponto médio da escala (3) e próximas do ponto máximo, o que indica uma adequação desses elementos enquanto representativos da aids. Contudo, tais elementos foram escolhidos para a escala por suas consensualidades no núcleo central de representações da aids em pesquisas com grupos populacionais diferentes do testado aqui. Sugere-se, para estudos futuros, que levantamentos de elementos (técnica de evocação livre) para compor a escala de valorização sejam realizados com amostras do mesmo grupo a ser examinado.

$\mathrm{O}$ agrupamento entre os elementos aqui testados mostrou uma coerência interpretativa possível de ser aventada em três dimensões: 1- Responsabilidade diante a prevenção sexual; 2-Doença causadora de morte e sofrimento; 3- Medo perante o preconceito. Destaca-se que os conectores lógicos entre os elementos precisam ser inferidos; entretanto, a despeito da inferência conectiva, a técnica fatorial fornece dados consistentes sobre as interconexões entre esses elementos. Diante desses resultados, considera-se a análise estrutural de representações sociais através dos níveis de valorização sim-

Tabela 2. Matriz componencial dos elementos das representações sociais da Aids.

\begin{tabular}{lccc}
\hline & & $\frac{\text { Cargas }}{\text { Dimensão }}$ & Dimensão \\
Elementos & Dimensão & 2 & 3 \\
\hline preservativo & 0,75 & & \\
cuidado & 0,74 & & \\
prevenção & 0,59 & & \\
sexo & 0,59 & & \\
responsabilidade & 0,47 & & \\
morte & & 0,81 & $-0,83$ \\
doença & & 0,70 & $-0,79$ \\
sofrimento & & 0,62 & \\
preconceito & & & \\
medo & & & \\
\hline
\end{tabular}

Nota. Foram suprimidas as cargas menores que 0,45 . 
bólica e agrupamentos entre elementos por correlações uma alternativa válida na investigação de representações sociais.

Por fim, estudos futuros que utilizem esta técnica para caracterizar a estrutura de uma representação social devem levar em conta que se trata de uma técnica secundária, que exige um levantamento prévio de símbolos vinculados ao objeto de representação. Portanto, não deve ser utilizada como única via de fornecer dados sobre representações sociais.

\section{Referências}

Abric, J. C. (2001). O estudo experimental das representações sociais. In D. Jodelet (Ed.), As representações sociais (pp. 155-171). Rio de Janeiro: UERJ.

Camargo, B. V., Barbará, A., \& Bertoldo, R. B. (2007). Concepção pragmática e científica dos adolescentes sobre a aids. Psicologia em Estudo, 12(2), 277-284.

Flament, C. (2001). Estrutura e dinâmica das representações sociais. In D. Jodelet (Ed.), As representações sociais (pp. 173-186). Rio de Janeiro: UERJ.

Flores-Palacios, F., \& Leyva-Flores, R. (2003). Representación social del SIDA en estudiantes de la Ciudad de México. Salud Publica de México, 45(5), 624-631.

Goodwin, R., Kozlova, A., Kwiatkowska, A., Luu, L. A. N., Nizharadze, G., Realo, A., Külvet, A., \& Rämmer, A. (2003). Social representations of HIV/AIDS in central and eastern Europe. Social Science and Medicine, 56, 1373-1384.
Marques, S. C., Oliveira, D. C., \& Gomes, A. M. T. (2004). Aids e representações sociais: uma análise comparativa entre subgrupos de trabalhadores. Psicologia: Teoria e Prática, Especial, 91-104.

Moscovici, S. (2003). O fenômeno das representações sociais. In S. Moscovici (Ed.), Representações sociais: Investigações em psicologia social (pp. 7-109). Petrópolis: Vozes.

Natividade, J. C. (2010). Relações entre representações sociais e conhecimento científico sobre HIV/Aids. Dissertação de Mestrado, Universidade Federal de Santa Catarina, Florianópolis.

Wagner, W. (1998). Sócio-gênese e características das representações sociais. In A. S. P. Moreira, \& D. C. de Oliveira. (Eds.), Estudos interdisciplinares de representação social (pp. 3-25). Goiânia: AB.

\author{
Recebido em 07.07.2010 \\ Primeira decisão editorial em 01.06.2011 \\ Versão final em 30.11.2011 \\ Aceito em 30.11.2011
}

